\title{
A complete biomimetic iron-sulfur cubane redox series
}

Liam Grunwald ${ }^{1}$, Martin Clémancey ${ }^{2}$, Daniel Klose ${ }^{1}$, Lionel Dubois ${ }^{3}$, Serge Gambarelli ${ }^{3}$, Gunnar Jeschke $^{1}$, Michael Wörle ${ }^{1}$, Geneviève Blondin ${ }^{2}$ and Victor Mougel ${ }^{1 *}$.

${ }^{1}$ Department of Chemistry and Applied Biosciences (D-CHAB), ETH Zürich, Vladimir-PrelogWeg 1-5/10, CH-8093 Zürich, Switzerland

${ }^{2}$ Univ. Grenoble Alpes, CNRS, CEA, IRIG, Laboratoire de Chimie et Biologie des Métaux, PMB, CEA Grenoble, 17 Avenue des Martyrs, F-38054 Grenoble Cedex, France

${ }^{3}$ Univ. Grenoble Alpes, Univ. Grenoble Alpes, CNRS, CEA/IRIG-SyMMES, 17 Rue des Martyrs, F-38054 Grenoble, Cedex, France

*Correspondence to: mougel@inorg.chem.ethz.ch

\begin{abstract}
Synthetic iron-sulfur cubanes are essential models for biological cofactors in the more complex enzymatic environments. However, a complete series of $\left[\mathrm{Fe}_{4} \mathrm{~S}_{4}\right]^{n}$ complexes spanning all biorelevant oxidation states $(n=0-3+)$ has never been prepared. Here, we demonstrate that the use of a bulky arylthiolate ligand promoting the encapsulation of alkali-metal cations in the vicinity of the cubane enables the synthesis of such a series. Characterization by EPR, ${ }^{57} \mathrm{Fe}$ Mössbauer spectroscopy, UV-Vis electronic absorption and variable-temperature X-ray diffraction analysis reveals key trends for the $\mathrm{Fe}_{4} \mathrm{~S}_{4}$ core's geometry as well as for the Mössbauer isomer shift, which both correlate systematically with oxidation state. Furthermore, we confirm the $S=4$ electronic ground state of the most reduced member, $\left[\mathrm{Fe}_{4} \mathrm{~S}_{4}\right]^{0}$, in agreement with that proposed for the allferrous cubanes in Nature.
\end{abstract}


Iron-sulfur (FeS) clusters are ubiquitous metallocofactors, driving the crucial biological processes to enable life on earth, ranging from iron homeostasis and gene regulation to multielectron transfer and enzymatic catalysis (1-5). Among them, cuboidal $\mathrm{Fe}_{4} \mathrm{~S}_{4}$ clusters bearing cysteine ligands are the most represented structures and are found in a large number of biological systems as mediators of long-range electron transfers or directly as catalytic active sites of enzymes. This central role is a consequence of the $\mathrm{Fe}_{4} \mathrm{~S}_{4}$ cluster's ability to undergo redox changes and reversibly mediate electron transfers with low energy barriers and therefore high efficiency. In natural enzymatic systems, $\left[\mathrm{Fe}_{4} \mathrm{~S}_{4}\right]^{0 / 1+/ 2+/ 3+}$ oxidation states have been observed: $\left[\mathrm{Fe}_{4} \mathrm{~S}_{4}\right]^{1+/ 2+}$ is the most frequently encountered redox couple and acts reductively, the oxidative $\left[\mathrm{Fe}_{4} \mathrm{~S}_{4}\right]^{2+/ 3+}$ couple is found in high-potential iron-sulfur proteins (HiPIPs), while the highly reducing $\left[\mathrm{Fe}_{4} \mathrm{~S}_{4}\right]^{0}$ state has only been found in the nitrogenase iron protein $(\mathrm{FeP})$.

The unambiguous identification of redox states and the in-depth understanding of the inorganic core structures in these natural systems has been directly enabled by the synthesis and study of well-defined $\left[\mathrm{Fe}_{4} \mathrm{~S}_{4}(\mathrm{SR})_{4}\right]^{n-}$ molecular analogues, whose spectroscopic signatures are key to identify sites suggested in enzymes. However, nearly 50 years after the initial discovery of $\mathrm{Fe}_{4} \mathrm{~S}_{4}$ models by Holm and among the hundreds of reported molecular $\mathrm{Fe}_{4} \mathrm{~S}_{4}$ clusters, a synthetic series of all biologically relevant oxidation states, $\left[\mathrm{Fe}_{4} \mathrm{~S}_{4}\right]^{0 / 1+/ 2+/ 3+}$, with the same ligand set has never been successfully completed. This prevents the systematic comparison of key parameters such as the core metrics of the $\mathrm{Fe}_{4} \mathrm{~S}_{4}$ motif (5-7). One of the main hurdles to the preparation of such a synthetic series originates from the challenge to isolate its most reduced member; due to its extreme sensitivity toward oxidative degradation, $\left[\mathrm{Fe}_{4} \mathrm{~S}_{4}(\mathrm{SR})_{4}\right]^{4-}$ remains the only analogue of the $\left[\mathrm{Fe}_{4} \mathrm{~S}_{4}(\mathrm{SR})_{4}\right]^{n-}(n=1-4)$ redox series which was never synthetically isolated. This so-called superreduced all-ferrous state of the $\mathrm{Fe}_{4} \mathrm{~S}_{4}$ core, $\left[\mathrm{Fe}_{4} \mathrm{~S}_{4}\right]^{0}$, was first detected electrochemically in 1984 by Pickett $(8)$ on a synthetic model of the biologically relevant $\left[\mathrm{Fe}_{4} \mathrm{~S}_{4}\left(\mathrm{~S}^{\mathrm{Cys}}\right)_{4}\right]^{n-}$ site, $\left[\mathrm{Fe}_{4} \mathrm{~S}_{4}(\mathrm{SPh})_{4}\right]^{n-}(9,10)$, before being proposed to exist in the nitrogenase FeP (11-13). Recent studies suggested that the ability of the FeP to access the superreduced state in operando enables the enzyme to operate at twice the efficiency in terms of ATP consumed per electron transferred than when operating with the $\left[\mathrm{Fe}_{4} \mathrm{~S}_{4}\right]^{1+/ 2+}$ couple $(2,14)$. In addition, reduction to the all-ferrous state of the $\mathrm{FeP}$ isolated from Methanosarcina acetivorans was shown to catalyze the conversion of $\mathrm{C} 1$ substrates such as $\mathrm{CO}_{2}$ and $\mathrm{CO}$ into hydrocarbons under ambient conditions (15). Last, as a biological synthon, the superreduced $\mathrm{FeS}$ cubane has been proposed to play a role during the maturation of the nitrogenase P-cluster $(16,17)$. However, the complexity of the FeP's enzymatic system has prevented the accurate determination of key structural and electronic parameters of the superreduced FeS core, notably (i) the possible electronic ground states for the all-ferrous FeP, namely $S=4$ or $S=0(12,14)$, (ii) the UV-Vis signature for the all ferrous state at $520 \mathrm{~nm}$, which is debated as possibly originating from the Ti(III)-citrate reducing agent used to obtain the superreduced state and, (iii), the metrics of the superreduced [ $\left.\mathrm{Fe}_{4} \mathrm{~S}_{4}\right]$ core. Hence, the identification of the all-ferrous state in biological systems triggered an intense quest for welldefined physiologically relevant molecular models. In 1996, Holm and co-workers reported that the phosphine supported $\left[\mathrm{Fe}_{4} \mathrm{~S}_{4}\right]^{0}$ cluster could be generated transiently in solution, but rapidly aggregates to form the more stable edge-fused all-ferrous $\left[\mathrm{Fe}_{8} \mathrm{~S}_{8}\right]^{0}$ and $\left[\mathrm{Fe}_{16} \mathrm{~S}_{16}\right]^{0}$ clusters over time (18). A milestone for the understanding of the geometric and electronic structure of the $\left[\mathrm{Fe}_{4} \mathrm{~S}_{4}\right]^{0}$ unit has been the utilization of non-physiological cyanide and $\mathrm{N}$-heterocyclic carbene (NHC) ligands by Holm and Deng in 2005 and 2008, respectively, which enabled the first structural characterization of the $\left[\mathrm{Fe}_{4} \mathrm{~S}_{4}\right]^{0}$ core in a molecular model (19-21). The stability of the NHC supported cubane allowed for a detailed spectroscopic characterization, revealing parameters 
reminiscent of biological data $(12,22)$. Nevertheless, NHC ligand properties differ significantly from the biologically relevant thiolate ligands; up to $15-30 \%$ of the metal-carbene orbital interaction energy originates from $\pi$-type metal-ligand back-bonding (23). On the contrary, thiolate ligands are stronger $\sigma$-and $\pi$-donors, creating a much weaker ligand field. This difference in binding character could alter the cluster's reactivity and spectroscopic properties.

In this work, we demonstrate that a careful choice of bulky thiolate ligand and counter-cation as well as strict exclusion of coordinating solvents enables the synthesis of a series of thiolatesupported FeS cubanes covering all biologically relevant oxidation states, ranging from the oxidized form of HiPIPs $\left(\left[\mathrm{Fe}_{4} \mathrm{~S}_{4}\right]^{3+}\right)$ to the all-ferrous form of the $\mathrm{FeP}\left(\left[\mathrm{Fe}_{4} \mathrm{~S}_{4}\right]^{0}\right)$. This permits a comprehensive analysis of the variation of the essential structural and electronic properties along the series by UV-Vis absorption, electron paramagnetic resonance (EPR), ${ }^{57} \mathrm{Fe}$ Mössbauer and single-crystal X-ray diffraction (XRD) analysis.

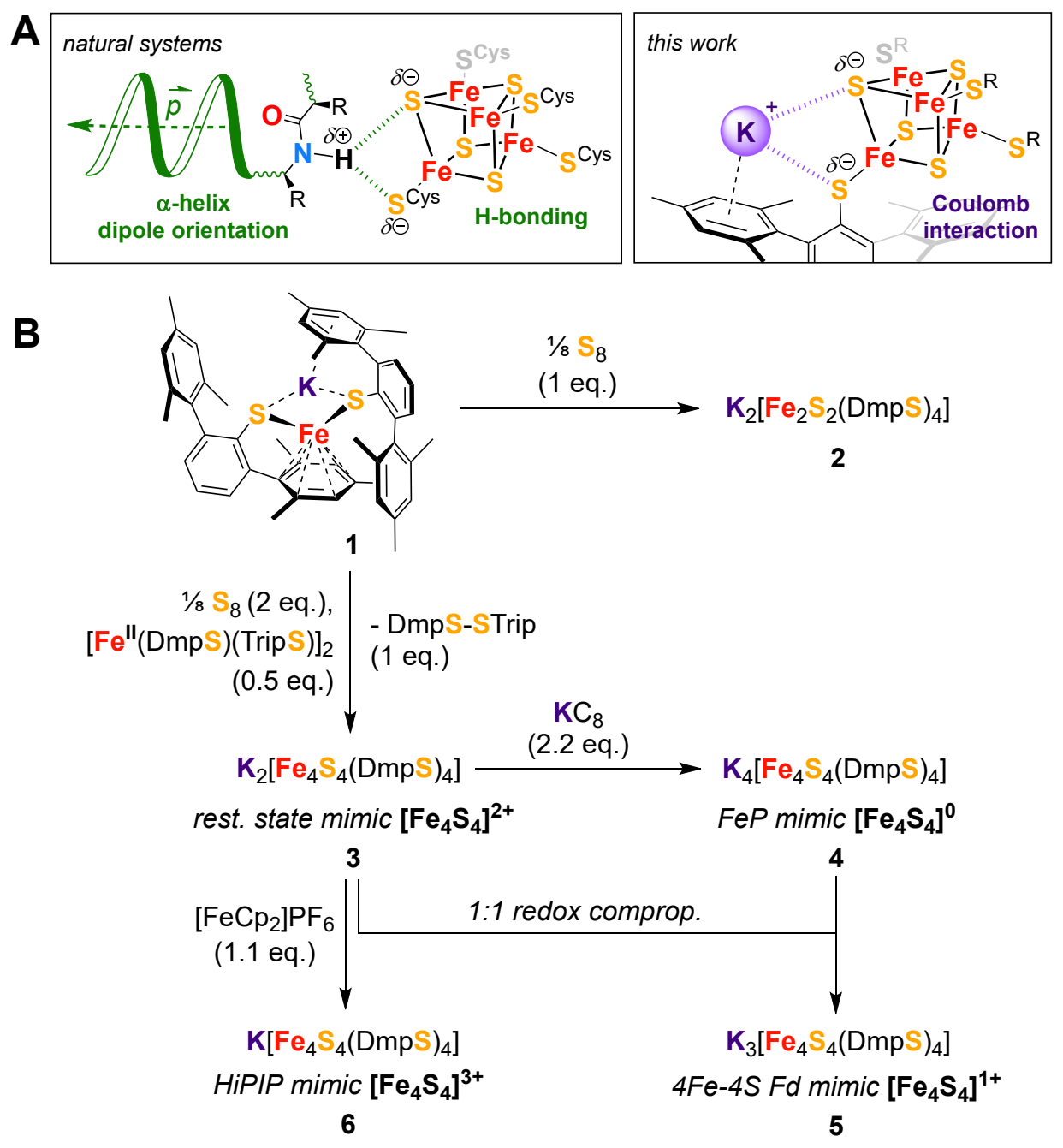

Fig. 1. Synthetic strategy utilized for the isolation and characterization of the redox series $\mathrm{K}_{n}\left[\mathrm{Fe}_{4} \mathrm{~S}_{4}(\mathrm{DmpS})_{4}\right](n=1-4)$. A Stabilization of reduced FeS cubanes in enzymes versus the strategy deployed in this work. B Schematic depiction of syntheses, whereby all reactions were carried out in toluene as solvent. Enzymatic systems and their active redox states relevant for the molecular models are indicated alongside. 
Two rather unique features of the FeS cluster in $\mathrm{FeP}$ were proposed to play a role in facilitating its reduction to the superreduced state, namely its arrangement at the positive end of four $\alpha$-helix dipoles and the distinct hydrogen bonding patterns surrounding the cluster (Fig. 1A \& S1) (2). The latter were found to be modulated upon variation of the oxidation state, adapting the environment to the cluster charge $(24,25)$. Interestingly, similar changes in hydrogen bonding patterns are also found for oxidized HiPIPs (26). Intending to mimic these stabilizing effects, we selected the bulky thiolate ligand $\mathrm{DmpS}^{-}\left(\mathrm{DmpS}^{-}=2,2{ }^{\prime}, 4,4{ }^{\prime}, 6,6\right.$ ' '-hexamethyl-1,1':3',1',-terphenyl-2'-thiolate) as a suitable candidate because of its ability to pack redox innocent $\mathrm{K}^{+}$ions into the molecular assembly formed upon coordination to metal centers by cation- $\pi$ interaction (Fig. 1B) $(27,28)$.

A significant number of strategies for $\left[\mathrm{Fe}_{4} \mathrm{~S}_{4}\right]^{2+}$ cluster synthesis have been reported, but most of them involve the combination of complex mixtures of sulfide sources, ligands, iron precursors and the frequent use of other additives such as bases. As a consequence, redox-sensitive coordinating solvents able to dissociate ionic species such as acetonitrile or methanol are typically required to solubilize these precursors, yet preclude the isolation of highly reduced clusters. Thus, to perform the initial cubane assembly in redox-tolerant non-coordinating media with as few reagents as possible, we developed the synthesis of the mononuclear homoleptic Fe ${ }^{\mathrm{I}}$-thiolate complex, $\mathrm{K}\left[\mathrm{Fe}(\mathrm{DmpS})_{2}\right]$ (1). This highly reduced $\mathrm{Fe}^{\mathrm{I}}$ precursor has the potential to act as a two-electron reductant for the generation of sulfido ligands, $\mathrm{S}^{2-}$, from elemental sulfur, while being also a source of $\mathrm{K}^{+}$counter-ions and bulky DmpS ${ }^{-}$ligands (refer to the Supplementary Materials for synthetic and characterization details). However, initial attempts to generate the $\left[\mathrm{Fe}_{4} \mathrm{~S}_{4}\right]^{2+}$ complex upon reaction of 1 with elemental sulfur in toluene instead resulted in the formation of the dimeric complex $\mathrm{K}_{2}\left[\mathrm{Fe}_{2} \mathrm{~S}_{2}(\mathrm{DmpS})_{4}\right]$ (2) (Fig. 1B \& S22). We reasoned that the isolation of such an $\mathrm{Fe}_{2} \mathrm{~S}_{2}$ dimer resulted from the fact that the high steric hinderance of $\mathrm{DmpS}^{-}$deterred its reactivity as a reducing agent, in contrast to the typical behavior observed in traditional conditions with smaller thiolate ligands, leading to $\left[\mathrm{Fe}_{4} \mathrm{~S}_{4}\right]^{2+}$ assemblies $(29,30)$. Under this assumption, we substituted $1 / 2$ equivalent of 1 for $1 / 4$ equivalents of $[\mathrm{Fe}(\mathrm{DmpS})(\mathrm{TripS})]_{2}(31)$ in the aforementioned conditions, which allowed us to isolate the dark yellow cubane, $\mathrm{K}_{2}\left[\mathrm{Fe}_{4} \mathrm{~S}_{4}(\mathrm{DmpS})_{4}\right](3)$, in $68 \%$ yield (Fig. 1B). 3 exhibits diamagnetic ${ }^{1} \mathrm{H}$ and ${ }^{13} \mathrm{C}$ NMR spectra accounting for all signals of the DmpS ${ }^{-}$ligand (Fig. S7-S10). Its UV-Vis absorption spectrum shows two characteristic bands at 340 and $404 \mathrm{~nm}$ (Fig. 3D), similar to other $\left[\mathrm{Fe}_{4} \mathrm{~S}_{4}\right]^{2+}$ cubanes supported by aromatic thiolates (9). In the solid-state, 3 crystallizes twofold twinned in the space-group P $2{ }_{1} 2{ }_{1} 2$ (No. 18) and contains two potassium ions, which are tightly packed around the central $\left[\mathrm{Fe}_{4} \mathrm{~S}_{4}\right]^{2+}$ motif (Fig. 2A) aided by cation- $\pi$ interactions from the surrounding mesityl substituents. These interactions likely play an important role to prevent the dissociation of the cation-anion pairs and maintain $\mathbf{3}$ as a neutral molecular assembly, soluble in non-coordinating aromatic solvents. 


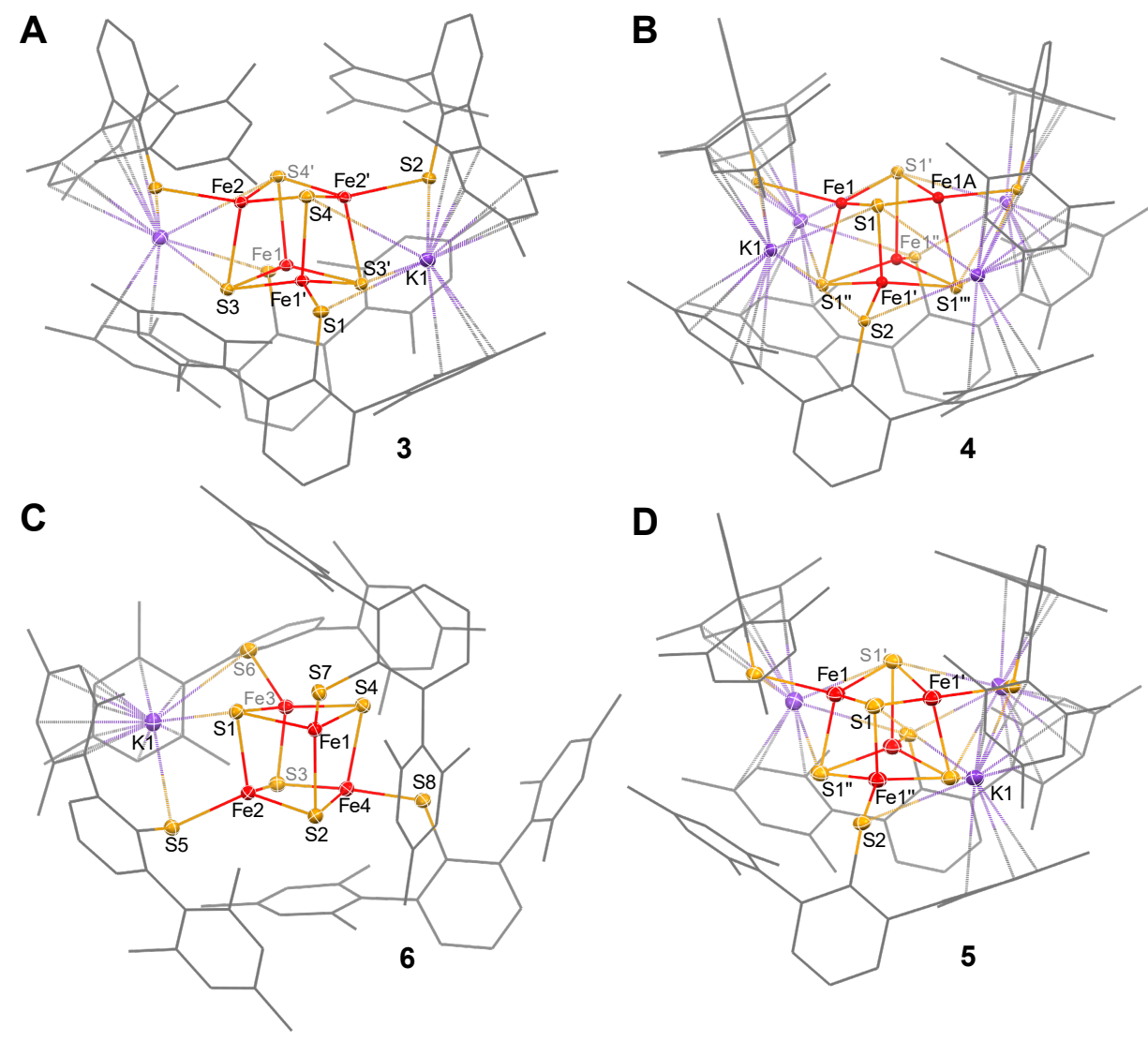

Fig. 2. Solid-state molecular structures of 3 (A), 4 (B), 6 (C) and 5 (D), in crystals of $\mathrm{K}_{2}\left[\mathrm{Fe}_{4} \mathrm{~S}_{4}(\mathrm{DmpS})_{4}\right] \cdot 2 \mathrm{HMDSO}, \mathrm{K}_{4}\left[\mathrm{Fe}_{4} \mathrm{~S}_{4}(\mathrm{DmpS})_{4}\right] \cdot 2 \mathrm{HMDSO}, \mathrm{K}_{3}\left[\mathrm{Fe}_{4} \mathrm{~S}_{4}(\mathrm{DmpS})_{4}\right] \cdot 2 \mathrm{HMDSO}$ and $\mathrm{K}\left[\mathrm{Fe}_{4} \mathrm{~S}_{4}(\mathrm{DmpS})_{4}\right] \cdot \mathrm{C}_{7} \mathrm{H}_{8}$, respectively. Co-crystallized solvent molecules as well as hydrogen atoms were omitted for clarity. Thermal ellipsoids at the $50 \%$ probability level are shown only for the Fe, S and K atoms. Detailed structural parameters of 3-6 are summarized in Table S8 and Tables S3-S6.

The cyclic voltammogram of 3 in $\left\{\left[{ }^{n} \mathrm{Bu}_{4} \mathrm{~N}\right]\left[\mathrm{BF}_{4}\right] \cdot 3\right.$ toluene $\}$ shows three redox events at $-2.10,-0.85$ and $-0.07 \mathrm{~V}$ versus $\mathrm{Fc} / \mathrm{Fc}^{+}$, corresponding to the $\left[\mathrm{Fe}_{4} \mathrm{~S}_{4}\right]^{1+/ 2+},\left[\mathrm{Fe}_{4} \mathrm{~S}_{4}\right]^{2+/ 3+}$ and $\left[\mathrm{Fe}_{4} \mathrm{~S}_{4}\right]^{3+/ 4+}$ couples, respectively. The $\left[\mathrm{Fe}_{4} \mathrm{~S}_{4}\right]^{0 / 1+}$ couple could not be observed, likely laying outside the potential window accessible in this electrolyte (Fig. S3). Nevertheless, the complete redox series could be accessed chemically (Fig. 1B): the all-ferrous $\left[\mathrm{Fe}_{4} \mathrm{~S}_{4}\right]^{0}$ cluster was isolated as the dark red complex $\mathrm{K}_{4}\left[\mathrm{Fe}_{4} \mathrm{~S}_{4}(\mathrm{DmpS})_{4}\right]$ (4) (Fig. 2B) upon reduction of 3 with 2.2 equivalents of potassium graphite, while the brown singly reduced $\left[\mathrm{Fe}_{4} \mathrm{~S}_{4}\right]^{1+}$ cluster, $\mathrm{K}_{3}\left[\mathrm{Fe}_{4} \mathrm{~S}_{4}(\mathrm{DmpS})_{4}\right]$ (5) (Fig. 2D), was prepared by comproportionation of $\mathbf{3}$ and $\mathbf{4}$. The singly oxidized $\left[\mathrm{Fe}_{4} \mathrm{~S}_{4}\right]^{3+}$ cluster was synthesized by oxidation of $\mathbf{3}$ with ferrocenium hexafluorophosphate, yielding the dark purple complex $\mathrm{K}\left[\mathrm{Fe}_{4} \mathrm{~S}_{4}(\mathrm{DmpS})_{4}\right]$ (6) (Fig. 2C; refer to the Supplementary Materials for further details). Hereby, each redox transformation is accompanied by the removal (oxidation) or the addition (reduction) of an encapsulated $\mathrm{K}^{+}$-ion. Such a modulation of the positive charges surrounding the cluster parallels well the varying number of $\mathrm{H}$-bonding interactions of $\mu^{3}$-sulfido and $\mu^{1}$-thiolato ligands to the protein envelope observed with $\mathrm{Fe}_{4} \mathrm{~S}_{4}$ cofactors in biological systems and found to be key to control the stability and redox potential of their different oxidation states $(2,24-26)$. 
Ultimately, the preparation of 3-6 enables a systematic approach to delineate the essential spectroscopic signatures of FeS cubanes in varying oxidation states. These signatures could, in turn, be used to facilitate the assignment of $\left[\mathrm{Fe}_{4} \mathrm{~S}_{4}\right]^{n+}$ oxidation states in the more complex biological environments with high certainty.

Compounds 3-6 were therefore characterized by ${ }^{57} \mathrm{Fe}$ Mössbauer spectroscopy. $80 \mathrm{~K}$ spectra were recorded on the complete series of complexes and are reproduced in Fig. 3A. As usually observed, two main lines are detected in the spectra of compounds $\mathbf{3}, \mathbf{5}$ and $\mathbf{6}$. Because they present slightly different profiles, spectra were simulated with two doublets. The nuclear parameters are listed in Table S1. In contrast, the spectrum of $\mathbf{4}$ presents broader lines evidencing four different sites. Simulations revealed similar isomer shift values for the four sites (from 0.59 to $0.65 \mathrm{~mm} \cdot \mathrm{s}^{-1}$ ) whereas the quadrupole splitting values vary in a large domain. As expected, the comparison of the $80 \mathrm{~K}$ spectra clearly evidences a decrease of the velocity corresponding to the central position of the absorption upon increase of the oxidation state of the complexes. Values from Table S1 are compiled in Fig. 3C. The four points are indeed aligned, and a linear fit indicates a loss of $0.08(2) \mathrm{mm} \cdot \mathrm{s}^{-1}$ for the isomer shift per additional ferric ion.

Additionally, paramagnetic compounds 4-6 were analyzed by perpendicular-mode EPR spectroscopy. A frozen toluene solution of $\mathbf{5}$ exhibits an EPR spectrum consisting of two components with $S=3 / 2$ and $S=1 / 2$, presenting $g$-values of $(3.05,2.64,2.16)$ and $(1.91,1.98,2.12)$, respectively (Fig. 3B \& S16A), and possessing nearly equal weights both at $6 \mathrm{~K}$ and at $10 \mathrm{~K}$. This suggests that both spin states are possible ground states here, as previously reported for synthetic and natural $\left[\mathrm{Fe}_{4} \mathrm{~S}_{4}\right]^{1+}$ systems $(32,33)$. The $S=3 / 2$ component appears to be stronger populated in the solid-state, as evident from the spectra shown in Fig. S16C, where the $S=1 / 2$ contribution disappears entirely upon immobilization of powdered $\mathbf{5}$ in eicosane. Comparatively, the X-band perpendicular mode EPR spectrum of $\mathbf{4}$ exhibits broad transitions at low field and significantly differs from the $S=3 / 2$ spectrum. Similarly with what had been observed for the $S=4$ ground state with biological Ti(III)-citrate reduced all ferrous FeS clusters $(12,34)$, the absence of transitions around $g=2$ even at temperatures down to $5 \mathrm{~K}$ (Fig. S15) underlines the integer-spin nature and, thus, all-ferrous oxidation state of 4 . The oxidized cubane, $\mathbf{6}$, shows a rhombic EPR spectrum with principal $g$-values of $(2.072,2.042,2.011)$ and a visible $g$-anisotropy, which is likewise in line with the $S=1 / 2$ electronic ground state found in biology as well as for previous molecular models (Fig. 3B \& S17) (35-38). 

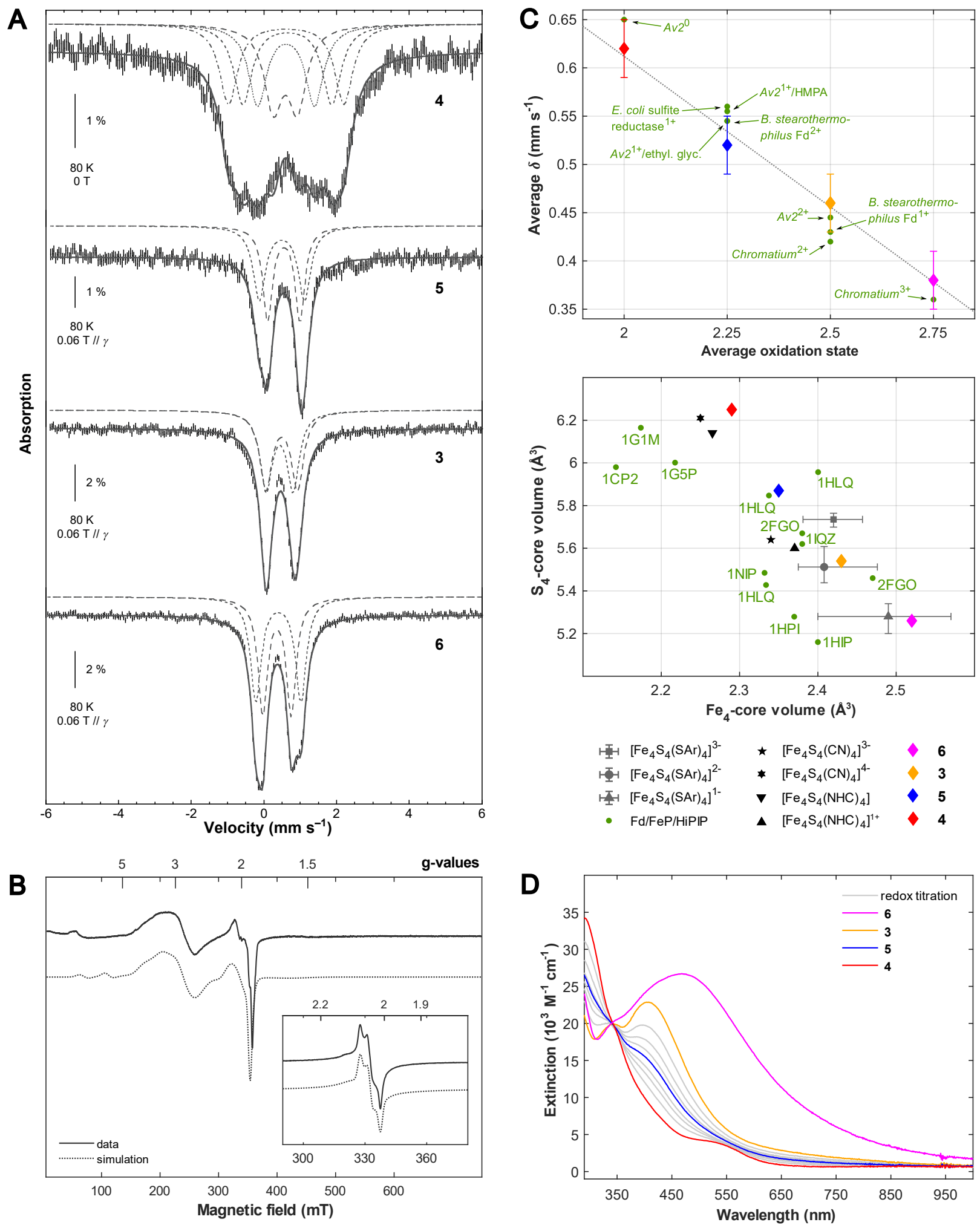

Fig. 3. ${ }^{57} \mathrm{Fe}$ Mössbauer, EPR, UV-Vis electronic absorption and geometric data for clusters 3-6. A Mössbauer spectra (hatched bars) recorded on powder samples at $80 \mathrm{~K}$ with a $0.06 \mathrm{~T}$ external magnetic field applied parallel to the $\gamma$-beam for $\mathbf{5 , 3}$ and $\mathbf{6}$ and at zero-field for 4 . Simulations are 
overlaid as grey solid lines and deconvolutions are displayed above. See Table S1 for the parameter values. B X-band perpendicular mode EPR spectra of $2 \mathrm{mM}$ toluene solutions of 5, recorded at $10 \mathrm{~K}$ and 6 (inset), recorded at $40 \mathrm{~K}$. Data are represented by solid lines and simulations by dotted ones. For details of the fitting parameters refer to Fig. S16 \& S17. C (top) Averaged value of the isomer shift issued from the simulations of the $80 \mathrm{~K}$ Mössbauer spectra upon the averaged oxidation state of the iron ions in complexes 3-6. The grey dotted line is a linear fit of the four experimental points. Data recorded on selected biological systems are shown alongside as green dots. $\mathbf{C}$ (bottom) Variation in the $\mathrm{Fe}_{4}$ - and $\mathrm{S}_{4}$-core volumes of selected $\mathrm{FeS}$ cubane containing structures of biological (FeP, 4Fe-4S Fds and HiPIP) and synthetic origin. Synthetic models of aromatic thiolate supported cubanes span 8,11 and 5 examples for $\left[\mathrm{Fe}_{4} \mathrm{~S}_{4}(\mathrm{SAr})_{4}\right]^{1-}$, $\left[\mathrm{Fe}_{4} \mathrm{~S}_{4}(\mathrm{SAr})_{4}\right]^{2-}$ , and $\left[\mathrm{Fe}_{4} \mathrm{~S}_{4}(\mathrm{SAr})_{4}\right]^{3-}$, respectively. The data are represented by a grey triangle, dot and square in the position of the arithmetic mean. Bars indicate the maximum and minimum values reported. Data for the redox series 3-6 are shown by diamonds; refer to Table S9 for all values and references. D UV-Vis electronic absorption spectra of $1.1 \cdot 10^{-4} \mathrm{M}$ toluene solutions of compounds 3 (yellow), 4 (red), 5 (blue) and $\mathbf{6}$ (magenta). Solid grey lines indicate spectra measured along the stoichiometric redox comproportionation reaction between $\mathbf{3}$ and $\mathbf{4}$, which results in formation of 5.

Upon sequential one-electron reduction, the UV-Vis absorption spectra of $\mathbf{6 , 3}, \mathbf{5}$ and $\mathbf{4}$ exhibit a decrease in intensity over most of the visible region, sharing an isosbestic point at approx. $350 \mathrm{~nm}$ (Fig. 3D). In the superreduced state, the otherwise featureless spectrum of 4 exhibits a pronounced shoulder at $520 \mathrm{~nm}$. The origin of this band, which is also observed in the Ti(III)-citrate reduced all-ferrous FeP, had been a topic of intense discussion, being attributed either to the all ferrous FeS cluster, or to the Ti(III)-citrate reducing agent (13). The unambiguous observation of this band in the UV-Vis spectrum of $\mathbf{4}$ demonstrates that it constitutes a spectroscopic signature of the all-ferrous $\left[\mathrm{Fe}_{4} \mathrm{~S}_{4}\right]^{0}$ core itself. Moreover, this band had been suggested to relate to the $S=4$ spinstate of the superreduced FeS core because it was not observed in the putative all-ferrous $S=0$ version of the FeP obtained by reduction with flavodoxin hydroquinone (14). This is in line with the spin state assignment for $\mathbf{4}$ proposed here and described below.

Besides the spectroscopic signatures, the solid-state molecular structures of compounds 3-6, bearing the same thiolate ligand (Fig. 2A-D) enable a systematic comparison of the metrics of the FeS cubane's core. To this end, structural parameters are summarized in Table S8. Within the redox series, the $\mathrm{Fe}_{4}$-core volume shows a decrease as the cubane gets reduced $\left(-0.08(1) \AA^{3}\right.$ per electron), in agreement with a stronger Coulomb-repulsion between the $\mathrm{S}^{2-}$ ligands and the reduced Fe-centers. Concomitantly, the $\mathrm{S}_{4}$-core volume rises $\left(+0.33(4) \AA^{3}\right.$ per electron), as shown in Fig. 3C. Because the increase in the $\mathrm{S}_{4}$-volume supersedes the decrease in the $\mathrm{Fe}_{4}$-volume, the total volume of the cubane as well as its surface area increase upon reduction, confirming the hypotheses of biological studies $(2,25,39)$. In a direct juxtaposition, the $\left[\mathrm{Fe}_{4} \mathrm{~S}_{4}\right]^{0 / 3+}$ cores of $\mathbf{4}$ and $\mathbf{6}$, respectively, exhibit low root-mean-square distances compared to structure data collected on the corresponding cofactors in their active redox state $(\operatorname{RMSD}(4 / 1 \mathrm{G} 1 \mathrm{M})=0.074$ and $\operatorname{RMSD}(6 / 1 \mathrm{HPI})=0.048$; see Fig. S32). Note that aside from the structural distortion of the FeS core and the packing of $\mathrm{K}^{+}$-ions, the overall connectivity and architecture of clusters 3-6 is invariant across all 4 oxidation states, exemplifying the ability of FeS cubanes to mediate multi-electron processes with marginal reorganization (Fig. 2). The data presented here provides a quantitative scale for systematic volume-changes occurring in the $\mathrm{Fe}_{4} \mathrm{~S}_{4}$ core upon variation of the oxidation state, which could facilitate redox assigments in the more complex enzymatic environments. Based on Fig. 3C, we propose two putative observations: (i) The Fe $\mathrm{F}_{4}$-volume appears generally 
underestimated; and (ii) a multitude of biological $\left[\mathrm{Fe}_{4} \mathrm{~S}_{4}\right]^{2+}$ or $\left[\mathrm{Fe}_{4} \mathrm{~S}_{4}\right]^{1+}$ sites - 1HLQ or 1CP2 for example - have been reported with metrics resemblant of more reduced forms, $\left[\mathrm{Fe}_{4} \mathrm{~S}_{4}\right]^{1+}$ or $\left[\mathrm{Fe}_{4} \mathrm{~S}_{4}\right]^{0}$ respectively, advocating the fact that oxidation state assignments in protein single crystals are not unambiguous and that the role of photoreduction in the X-ray beam is perhaps underrated (40).
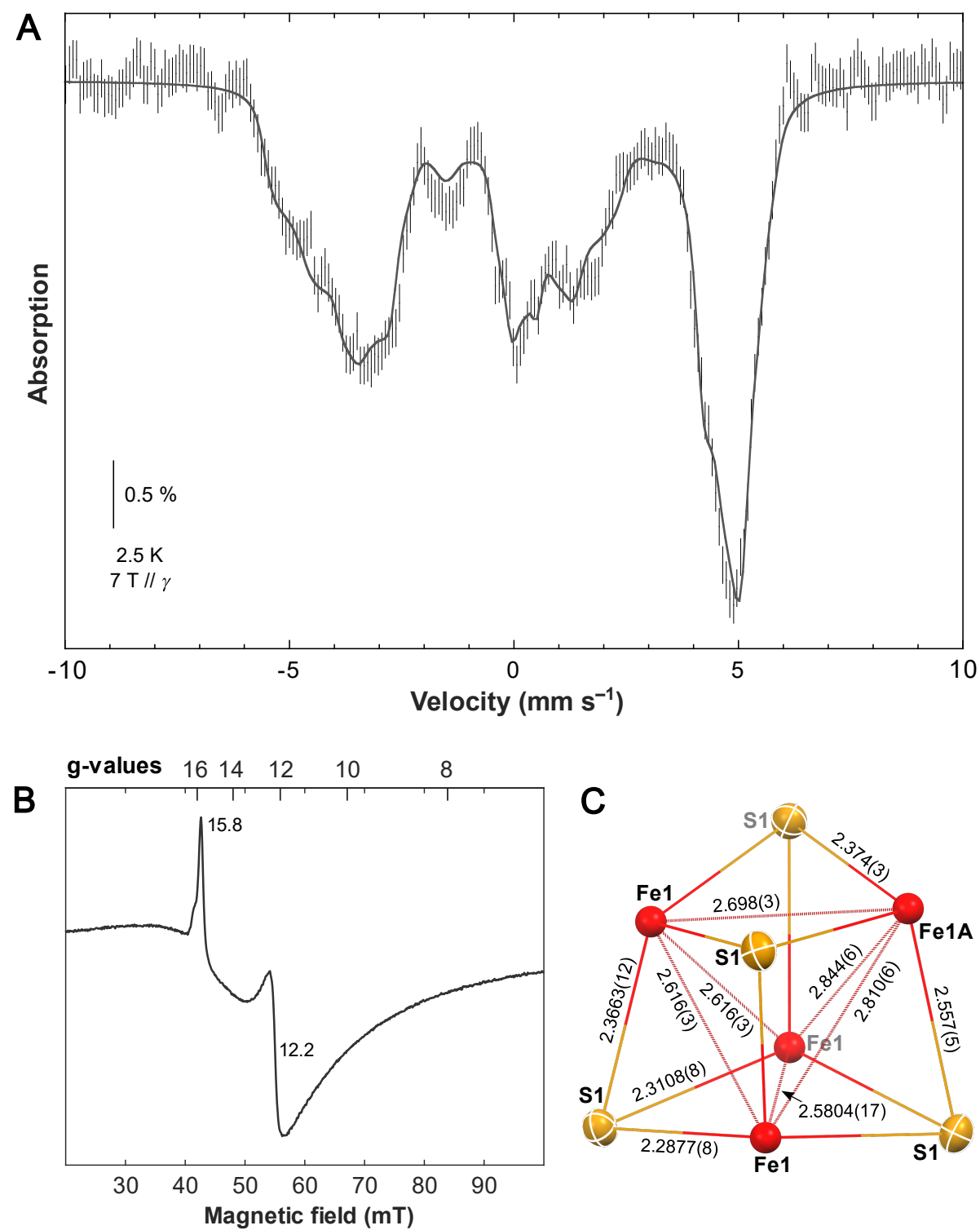

Fig. 4. Spectroscopic and structural data for 4. A $2.5 \mathrm{~K}$ Mössbauer spectrum recorded on a powder sample of 4 using a $7 \mathrm{~T}$ external magnetic field applied parallel to the $\gamma$-beam (hatched bars). A simulation is overlaid as a grey solid line and the corresponding list of parameters is given in Table S2. B Low-field region of the parallel-mode EPR spectrum of a $10 \mathrm{mM}$ frozen toluene/cyclohexane (9:1) solution of $\mathbf{4}$ recorded at $6 \mathrm{~K}$. C Solid-state molecular structure of the $\mathrm{Fe}_{4} \mathrm{~S}_{4}$-unit in 4 at $100 \mathrm{~K}$, containing three symmetry equivalent iron-atoms (Fe1-site with an occupancy of $0.797(8)$ ) and one iron-atom of the Fe1A-site with an occupancy of 0.203(8). The disorder described by the split model corresponds to a superposition of this locally ordered unit in four different orientations. Distances are given in $\AA$. 
Based on the results from UV-Vis absorption, zero-field ${ }^{57} \mathrm{Fe}$ Mössbauer and perpendicular-mode EPR spectroscopy presented above, a $S=4$ spin ground state may be suggested for 4 . To further confirm this assignment, applied-field ${ }^{57} \mathrm{Fe}$ Mössbauer, parallel-mode EPR and temperature dependent single-crystal XRD analyses were carried out. The $2.5 \mathrm{~K}$ and $7 \mathrm{~T}{ }^{57} \mathrm{Fe}$ Mössbauer spectrum of 4 (Fig. 4A) is very similar to that of Ti(III)citrate reduced Azobacter vinelandii (Av2), strongly advocating the $S=4$ ground state (41). Moreover, as for $A v 2$, upon subtraction of the $10 \mathrm{mT}$ spectrum recorded at $2.5 \mathrm{~K}$ from that recorded at $5.6 \mathrm{~K}$, the resulting difference can be deconvoluted in doublets, indicating a similar electronic structure. In contrast with $A v 2$ but in agreement with the $80 \mathrm{~K}$ spectrum shown above, they are four in a 1:1:1:1 ratio (Fig. S18). They present the same isomer shift, $\delta$, of $0.65 \mathrm{~mm} \cdot \mathrm{s}^{-1}$ (Table S2), a similar value to that determined for the all-ferrous cluster of $A v 2\left(0.68 \mathrm{~mm} \cdot \mathrm{s}^{-1}\right)$. The quadrupole splitting values, $\Delta E_{Q}$, range from 0.76 to $3.19 \mathrm{~mm} \cdot \mathrm{s}^{-1}$, a larger domain than that of the protein $\left(1.24-3.08 \mathrm{~mm} \cdot \mathrm{s}^{-1}\right)$. A simulation of the $2.5 \mathrm{~K}$ and $7 \mathrm{~T}$ spectrum of 4 is proposed in Fig. 4A (see Fig. S19 and Table S2 for the deconvolution and the parameter set, respectively). Only Site 1 presents positive hyperfine values, while Sites 2-4 have negative values, in fair agreement with the spin alignment expected for a $S=4$ ground state. The isotropic components $(4.0,-8.1,-7.8,-7.7 \mathrm{~T})$ are larger than those determined on the $\left[\mathrm{Fe}_{4} \mathrm{~S}_{4}\right]^{0}$ cluster isolated with a NHC-based ligand (20), and similar to those of $A v 2$. The

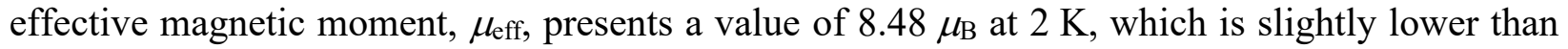
the expected spin-only value of $8.94 \mu_{\mathrm{B}}$ for a nonet, and increases to $9.82 \mu_{\mathrm{B}}$ at $300 \mathrm{~K}$ (Fig. S20), corroborating the $S=4$ assignment. Furthermore, the low field region of the EPR spectrum of a frozen solution of 4 recorded in parallel-mode exhibits two sharp features with $g$-values of 15.8 and 12.2. This agrees with the previous studies of $\left[\mathrm{Fe}_{4} \mathrm{~S}_{4}\right]^{0}$ clusters with $S=4$ ground states, leading us to attribute these transitions to the ground state doublet $\left(M_{S} \pm 4\right)$ and the first excited doublet $\left(M_{S}\right.$ \pm 3 ) of the $S=4$ manifold, respectively (Fig. 4B) $(12,20,34,41)$.

Such a $S=4$ spin state has been shown to give rise to a structural distortion of the $\mathrm{Fe}_{4} \mathrm{~S}_{4}$ core resulting in 3 symmetrically equivalent and 1 inequivalent sites (3:1 distortion) (20). This appears at first sight incompatible with the single-crystal XRD data recorded on 4 at $100 \mathrm{~K}$, as the proposed tetragonal space group $P \overline{4} 2{ }_{1}$ c (No. 114) imposes a fully symmetrical $\mathrm{Fe}_{4} \mathrm{~S}_{4}$-unit with a single $\mathrm{Fe}$ center in the asymmetric unit. However, a close inspection of the difference Fourier map for the single-crystal XRD data (Fig. S27) revealed that a single ellipsoid in the position of Fe1 cannot properly account for the observed electron density. Instead, a description applying a split model using two partially occupied iron sites proved to be superior. The refinement, constraining the sum of the occupancies to 1 and the isotropic displacement parameters for both split positions to be equal, converges at an occupancy ratio of $0.797(8): 0.203(8)$ at $100 \mathrm{~K}$ for Fel and Fe1A, respectively. This Fe1:Fe1A occupancy ratio of $80: 20$ is slightly higher than expected for the $S=4$ ground state, for which a 75:25 ratio should be adopted. Therefore, the evolution of the site occupancies was determined from a series of measurements performed at varying temperature. The extrapolation to $0 \mathrm{~K}$ gives an occupancy for Fe1 of almost exactly 0.75 , as it is expected for a fully occupied $S=4$ ground state (Fig. S30; for further details, refer to the Supplementary Materials). This is in line with the temperature dependence of the effective magnetic moment, $\mu_{\mathrm{eff}}$, which also shows a linear decrease with lower temperature until approximately $15 \mathrm{~K}$ (Fig. S20). Fe1A therefore corresponds to the antiferromagnetically aligned iron-site of the nonet spin-state, which perturbs the tetragonal symmetry $\left(P \overline{4} 2_{1}\right.$ c $)$ of the $\mathrm{Fe}_{4} \mathrm{~S}_{4}$ core due to magneto-structural correlation. This results in a domain of Fe-Fe and Fe-S distances in 4, ranging from 2.844(6) to $2.5804(17) \AA$ and from $2.557(5)$ to $2.2877(8) \AA$, respectively (Fig. 4C), being larger than that of 
the NHC-based system (21) and similar to what had been suggested based on computational and spectroscopic studies of the all-ferrous FeP (Table S9) (42, 43).

The solid-state structure and spectroscopic signature of superreduced all-ferrous $\mathbf{4}$ confirms the $S=4$ electronic ground state and provides a key argument in long-standing debates concerning the fundamental geometric and electronic structure of the hitherto elusive $\left[\mathrm{Fe}_{4} \mathrm{~S}_{4}\right]^{0}$ state of FeS cubane cofactors encountered in Nature. More broadly, we found that the use of thiolate ligands enabling the coordination of alkaline cations in the vicinity of the $\mu^{3}-\mathrm{S}^{2-}$ ligands via cation- $\pi$ interaction mimics the stabilizing H-bonding found in natural systems. Consequently, this proved to be a highly effective strategy for the synthesis of a complete redox series of FeS cubanes. This redox series, 3-6, enabled quantitatively uncovering key relationships between the oxidation state of the cubane, its Mössbauer isomer shift and the $\mathrm{Fe}_{4} \mathrm{~S}_{4}$ core's volumetric parameters. We expect these trends to aid the assignment of oxidation states of FeS cubanes in the more complex biological environments and are currently pursuing the in-depth spectroscopic and theoretical analysis of 36, which should lead to a rational understanding of the variation of their electronic structure.

Acknowledgments: J.-F. Jacquot is acknowledged for his assistance with SQUID measurements.

Funding: European Research Council (ERC) under the European Union's Horizon 2020 research and innovation programme (grant agreement No. [853064]) (LG, VM). MC and GB thank the Labex ARCANE and CBH-EUR-GS (ANR-17-EURE-0003) for funding.

Author contributions: Conceptualization: VM. Methodology: LG, VM. Validation: LG, MW, MC, DK, GB. Formal Analysis: LG, MW, MC, DK, GB, SG. Investigation: LG, MC, DK, LD, SG, GB. Data Curation: LG, MC, DK, GB, LD, SG. Writing - Original draft: LG, VM, GB. Writing - Review \& Editing: all authors. Visualization: LG, GB. Project Administration: VM. Funding Acquisition: VM, MW, GB, GJ.

Data and materials availability: The solid-state molecular structures of all compounds discussed have been deposited as CIF files in the Cambridge Structural database (CSD): 2124635 (4), 2124636 (2), 2124637 (3), 2124638 (5), 2124639 (6) and 2124640 (1). All other data are available in the main text or the Supplementary Materials.

\section{References:}

1. B. K. Burgess, D. J. Lowe, Mechanism of Molybdenum Nitrogenase. Chem. Rev. 96, 29833012 (1996).

2. H. L. Rutledge, F. A. Tezcan, Electron Transfer in Nitrogenase. Chem. Rev. 120, 51585193 (2020).

3. E. O'Brien et al., The [4Fe4S] cluster of human DNA primase functions as a redox switch using DNA charge transport. Science 355, 1789-1789 (2017).

4. N. Maio et al., Fe-S cofactors in the SARS-CoV-2 RNA-dependent RNA polymerase are potential antiviral targets. Science 373, 236-241 (2021). 
5. A. E. Boncella et al., The expanding utility of iron-sulfur clusters: Their functional roles in biology, synthetic small molecules, maquettes and artificial proteins, biomimetic materials, and therapeutic strategies. Coord. Chem. Rev., 214229 (2021).

6. P. Venkateswara Rao, R. H. Holm, Synthetic Analogues of the Active Sites of Iron-Sulfur Proteins. Chem. Rev. 104, 527-559 (2004).

7. S. C. Lee, W. Lo, R. H. Holm, Developments in the Biomimetic Chemistry of CubaneType and Higher Nuclearity Iron-Sulfur Clusters. Chem. Rev. 114, 3579-3600 (2014).

8. C. J. Pickett, A simple hydrocarbon electrolyte: Completing the electron-transfer series $\left[\mathrm{Fe}_{4} \mathrm{~S}_{4}(\mathrm{SPh})_{4}\right]^{1-/ 2-/ 3-/ 4-}$. J. Chem. Soc., Chem. Commun., 323-326 (1985).

9. B. V. DePamphilis, B. A. Averill, T. Herskovitz, L. Que, R. H. Holm, Synthetic analogs of the active sites of iron-sulfur proteins. VI. Spectral and redox characteristics of the tetranuclear clusters $\left[\mathrm{Fe}_{4} \mathrm{~S}_{4}(\mathrm{SR})_{4}\right]^{2+}$. J. Am. Chem. Soc. 96, 4159-4167 (1974).

10. E. J. Laskowski et al., Synthetic analogues of the 4-Fe active sites of reduced ferredoxins. Electronic properties of the tetranuclear trianions $\left[\mathrm{Fe}_{4} \mathrm{~S}_{4}(\mathrm{SR})_{4}\right]^{3-}$ and the structure of $\left[\left(\mathrm{C}_{2} \mathrm{H}_{5}\right)_{3}\left(\mathrm{CH}_{3}\right) \mathrm{N}\right]_{3}\left[\mathrm{Fe}_{4} \mathrm{~S}_{4}\left(\mathrm{SC}_{6} \mathrm{H}_{5}\right)_{4}\right]$. J. Am. Chem. Soc. 100, 5322-5337 (1978).

11. G. D. Watt, K. R. N. Reddy, Formation of an all ferrous $\mathrm{Fe}_{4} \mathrm{~S}_{4}$ cluster in the iron protein component of Azotobacter vinelandii nitrogenase. J. Inorg. Biochem. 53, 281-294 (1994).

12. H. C. Angove, S. J. Yoo, B. K. Burgess, E. Münck, Mössbauer and EPR Evidence for an All-Ferrous $\mathrm{Fe}_{4} \mathrm{~S}_{4}$ Cluster with $S=4$ in the Fe Protein of Nitrogenase. J. Am. Chem. Soc. 119, 8730-8731 (1997).

13. H. C. Angove, S. J. Yoo, E. Münck, B. K. Burgess, An all-ferrous state of the Fe protein of nitrogenase. Interaction with nucleotides and electron transfer to the MoFe protein. $J$. Biol. Chem. 273, 26330-26337 (1998).

14. T. J. Lowery et al., Flavodoxin hydroquinone reduces Azotobacter vinelandii Fe protein to the all-ferrous redox state with a $S=0$ spin state. Proc. Natl. Acad. Sci. U.S.A. 103, 1713117136 (2006).

15. J. B. Solomon et al., Probing the All-Ferrous States of Methanogen Nitrogenase Iron Proteins. JACS Au 1, 119-123 (2021).

16. S. Burén, E. Jiménez-Vicente, C. Echavarri-Erasun, L. M. Rubio, Biosynthesis of Nitrogenase Cofactors. Chem. Rev. 120, $4921-4968$ (2020).

17. K. Rupnik et al., Nonenzymatic Synthesis of the P-Cluster in the Nitrogenase MoFe Protein: Evidence of the Involvement of All-Ferrous $\left[\mathrm{Fe}_{4} \mathrm{~S}_{4}\right]^{0}$ Intermediates. Biochemistry 53, 1108-1116 (2014).

18. C. Goh, B. M. Segal, J. Huang, J. R. Long, R. H. Holm, Polycubane Clusters: Synthesis of $\left[\mathrm{Fe}_{4} \mathrm{~S}_{4}\left(\mathrm{PR}_{3}\right)_{4}\right]^{1+, 0}\left(\mathrm{R}=\mathrm{Bu}^{t}, \mathrm{Cy}, \mathrm{Pr}^{i}\right)$ and $\left[\mathrm{Fe}_{4} \mathrm{~S}_{4}\right]^{0}$ Core Aggregation upon Loss of Phosphine. J. Am. Chem. Soc. 118, 11844-11853 (1996).

19. T. A. Scott, C. P. Berlinguette, R. H. Holm, H. C. Zhou, Initial synthesis and structure of an all-ferrous analogue of the fully reduced $\left[\mathrm{Fe}_{4} \mathrm{~S}_{4}\right]^{0}$ cluster of the nitrogenase iron protein. Proc. Natl. Acad. Sci. U.S.A. 102, 9741-9744 (2005).

20. M. Chakrabarti, L. Deng, R. H. Holm, E. Münck, E. L. Bominaar, Mössbauer, Electron Paramagnetic Resonance, and Theoretical Studies of a Carbene-Based All-Ferrous $\mathrm{Fe}_{4} \mathrm{~S}_{4}$ Cluster: Electronic Origin and Structural Identification of the Unique Spectroscopic Site. Inorg. Chem. 48, 2735-2747 (2009).

21. L. Deng, R. H. Holm, Stabilization of Fully Reduced Iron-Sulfur Clusters by Carbene Ligation: The $\left[\mathrm{Fe}_{\mathrm{n}} \mathrm{S}_{\mathrm{n}}\right]^{0}$ Oxidation Levels $(\mathrm{n}=4,8)$. J. Am. Chem. Soc. 130, 9878-9886 (2008). 
22. E. Münck, E. L. Bominaar, Bringing Stability to Highly Reduced Iron-Sulfur Clusters. Science 321, 1452-1453 (2008).

23. X. Hu, I. Castro-Rodriguez, K. Olsen, K. Meyer, Group 11 Metal Complexes of NHeterocyclic Carbene Ligands: Nature of the MetalsCarbene Bond. Organometallics 23, 755-764 (2004).

24. B. B. Wenke, T. Spatzal, D. C. Rees, Site-Specific Oxidation State Assignments of the Iron Atoms in the $[4 \mathrm{Fe}: 4 \mathrm{~S}]^{2+1+/ 0}$ States of the Nitrogenase Fe-Protein. Angew. Chem. 131, 39343937 (2019).

25. P. Strop et al., Crystal structure of the all-ferrous $[4 \mathrm{Fe}-4 \mathrm{~S}]^{0}$ form of the nitrogenase iron protein from Azotobacter vinelandii. Biochemistry 40, 651-656 (2001).

26. A. Dey et al., Solvent Tuning of Electrochemical Potentials in the Active Sites of HiPIP Versus Ferredoxin. Science 318, 1464-1468 (2007).

27. M. Niemeyer, P. P. Power, Donor-Free Alkali Metal Thiolates: Synthesis and Structure of Dimeric, Trimeric, and Tetrameric Complexes with Sterically Encumbered Terphenyl Substituents. Inorg. Chem. 35, 7264-7272 (1996).

28. B. D. Rekken, T. M. Brown, M. M. Olmstead, J. C. Fettinger, P. P. Power, Stable Plumbylene Dichalcogenolate Monomers with Large Differences in Their Interligand Angles and the Synthesis and Characterization of a Monothiolato $\mathrm{Pb}(\mathrm{II})$ Bromide and Lithium Trithiolato Plumbate. Inorg. Chem. 52, 3054-3062 (2013).

29. T. Herskovitz et al., Structure and Properties of a Synthetic Analogue of Bacterial IronSulfur Proteins. Proc. Natl. Acad. Sci. U.S.A. 69, 2437-2441 (1972).

30. B. A. Averill, T. Herskovitz, R. H. Holm, J. A. Ibers, Synthetic analogs of the active sites of iron-sulfur proteins. II. Synthesis and structure of the tetra[mercapto- $\mu^{3}$-sulfido-iron] clusters, $\left[\mathrm{Fe}_{4} \mathrm{~S}_{4}(\mathrm{SR})_{4}\right]^{2+}$. J. Am. Chem. Soc. 95, 3523-3534 (1973).

31. Y. Ohki, Y. Ikagawa, K. Tatsumi, Synthesis of New [8Fe-7S] Clusters: A Topological Link between the Core Structures of P-Cluster, FeMo-co, and FeFe-co of Nitrogenases. $J$. Am. Chem. Soc. 129, 10457-10465 (2007).

32. M. J. Carney, G. C. Papaefthymiou, K. Spartalian, R. B. Frankel, R. H. Holm, Ground Spin State Variability in $\left[\mathrm{Fe}_{4} \mathrm{~S}_{4}(\mathrm{SR})_{4}\right]^{3-}$. Synthetic Analogues of the Reduced Clusters in Ferredoxins and Other Iron-Sulfur Proteins: Cases of Extreme Sensitivity of Electronic State and Structure to Extrinsic Factors. J. Am. Chem. Soc. 110, 6084-6095 (1988).

33. P. A. Lindahl, E. P. Day, T. A. Kent, W. H. Orme-Johnson, E. Münck, Mössbauer, EPR, and magnetization studies of the Azotobacter vinelandii $\mathrm{Fe}$ protein. Evidence for a [4Fe$4 \mathrm{~S}]]^{1+}$ cluster with spin $S=3 / 2$. J. Biol. Chem. 260, 11160-11173 (1985).

34. M. Hans, W. Buckel, E. Bill, Spectroscopic evidence for an all-ferrous $[4 \mathrm{Fe}-4 \mathrm{~S}]^{0}$ cluster in the superreduced activator of 2-hydroxyglutaryl-CoA dehydratase from Acidaminococcus fermentans. J. Biol. Inorg. Chem. 13, 563-574 (2008).

35. K. Tanifuji et al., A convenient route to synthetic analogues of the oxidized form of highpotential iron-sulfur proteins. Inorg. Chem. 53, 4000-4009 (2014).

36. T. O'Sullivan, M. M. Millar, Synthesis and Study of an Analogue for the $\left[\mathrm{Fe}_{4} \mathrm{~S}_{4}\right]^{3+} \mathrm{Center}$ of Oxidized High-Potential Iron-Sulfur Proteins. J. Am. Chem. Soc. 107, 4096-4097 (1985).

37. M. Stelter et al., Structure at $1.0 \AA$ resolution of a high-potential iron-sulfur protein involved in the aerobic respiratory chain of Rhodothermus marinus. J. Biol. Inorg. Chem.

15, 303-313 (2010). 
38. V. Papaefthymiou, M. M. Millar, E. Muenck, Moessbauer and EPR studies of a synthetic analog for the iron-sulfur $\mathrm{Fe}_{4} \mathrm{~S}_{4}$ core of oxidized and reduced high-potential iron proteins. Inorg. Chem. 25, 3010-3014 (1986).

39. M. M. Georgiadis et al., Crystallographic structure of the nitrogenase iron protein from Azotobacter vinelandii. Science 257, 1653-1659 (1992).

40. C. Nave, Radiation damage in protein crystallography. Radiat. Phys. Chem. 45, 483-490 (1995).

41. S. J. Yoo, H. C. Angove, B. K. Burgess, M. P. Hendrich, E. Münck, Mossbauer and integerspin EPR studies and spin-coupling analysis of the $[4 \mathrm{Fe}-4 \mathrm{~S}]^{0}$ cluster of the $\mathrm{Fe}$ protein from Azotobacter vinelandii nitrogenase. J. Am. Chem. Soc. 121, 2534-2545 (1999).

42. R. A. Torres, T. Lovell, L. Noodleman, D. A. Case, Density functional and reduction potential calculations of $\mathrm{Fe}_{4} \mathrm{~S}_{4}$ clusters. J. Am. Chem. Soc. 125, 1923-1936 (2003).

43. D. Mitra et al., Characterization of [4Fe-4S] Cluster Vibrations and Structure in Nitrogenase Fe Protein at Three Oxidation Levels via Combined NRVS, EXAFS, and DFT Analyses. J. Am. Chem. Soc. 135, 2530-2543 (2013). 